\title{
Research on the Interactive Mechanism of Scientific and Technological Innovation, Industrial Upgrading and Economic Growth
}

\author{
DING JiaJun and CHEN Sihang \\ School of Management, Yangtze University, Jingzhou Hubei, China \\ Email: dingjiajun117@126.com
}

\begin{abstract}
Scientific and technological innovation, industrial upgrading and economic growth are the hotspots of current theoretical and practical research, and they are also important issues in a country's macroeconomic development. This paper takes the interactive mechanism of scientific and technological innovation, industrial upgrading and economic growth as the research content, and analyzes the connotation and interactive mechanism of scientific and technological innovation, industrial upgrading and economic growth from the theoretical and practical aspects, in order to clarify the endogenous driving force and mechanism of economic growth in the new era.
\end{abstract}

Keywords: Scientific and technological innovation; industrial upgrading; economic growth

\section{Introduction}

At present, China's economy has entered a new normal, and traditional economic growth models that rely on resources and factors are unsustainable. We must look for new models of economic growth. China's economic growth faces three difficulties. The first is how to transform scientific and technological innovation into the endogenous driving force to promote economic growth. The second is how to upgrade the existing industries and release the new power of economic growth. The third is how to make economic growth serve industrial upgrading and scientific and technological innovation. To this end, this paper is based on this to explore the interactive mechanism of scientific and technological innovation, industrial upgrading and economic growth.

\section{Theoretical Analysis of Scientific and Technological Innovation, Industrial Upgrading and Economic Growth}

\subsection{Marx's Economic Theory}

Marx's classical theory holds that innovation can improve productivity and then obtain more relative surplus value. Taking the use of new machines produced by capitalist enterprises as an example, Marx analyzed the social process of technological innovation and pointed out that the process of using new machines to create relative surplus value is actually "changing the technological and social conditions of the labor process". It can be seen that Marx's works already contain the original ideas of technological innovation.

\section{$2.2 \quad$ New Growth Theory}

Romer considered that the spillover effect of knowledge and technology is a necessary condition for economic growth, and endogenous technological progress is the main reason for economic growth. Then he put forward a knowledge spillover model (Romer, 1986). Lucas used the spillover of human capital to

Author's brief introduction: Ding Jiajun (1989 -), female, from Heilongjiang Hegang, School of Management, Yangtze University, research direction: regional economic research; Chen Sihang (1987-), male, from Jiangxi Fengcheng, School of Management, Yangtze University, research direction: regional economy. 
explain technological progress and economic growth. He believed that the source of economic growth was the spillover of human capital of workers with special professional skills (Lucas, 1988). Therefore, the new economic growth theory holds that scientific and technological innovation can promote economic growth, and is the internal driving force of economic growth (Cheng Yu \& Chen Xue, 2013), and the knowledge and technical elements are renewable and infinite.

\subsection{Industrial Structure Evolution Theory}

Clark studied the law of industrial structure in economic development, pointing out that the development of economy and society will lead to the transfer of industrial structure from primary industry to secondary industry and then to tertiary industry (Clark,1960). Hirschman pointed out that due to the development of new technologies and new products, industries will shift from high-gradient areas to low-gradient areas (Hirschman, 1958). Therefore, industrial transfer and upgrading will promote the development of regional economy.

\subsection{Sustainable Development Theory}

The sustainable development theory holds that the traditional factor-driven economic development models are unsustainable, because most of the elements are tangible and unsustainable (Wang Zhijia \& Ke Jinliang, 1997). Later, scholars shifted their research into research on environmental protection and technological innovation, pointing out that they can stimulate more production potential through technological progress and further improve production efficiency. One of the views of sustainable development theory is that the knowledge economy is the trend and basis of sustainable development in the future, and knowledge and information technology are the main driving forces of economic development in the future.

\section{Analysis of the Interactive Mechanism of Scientific and Technological Innovation, Industrial Upgrading and Economic Growth}

Based on the above theoretical research, we further synthetically analyze the interactive mechanism of scientific and technological innovation, industrial upgrading and economic growth, and get the following three basic understandings.

\subsection{Scientific and Technological Innovation is the Endogenous Driving Force for Industrial Upgrading and Economic Growth}

Research shows that scientific and technological innovation can improve productivity through technological progress and transformation of scientific and technological achievements. Technological progress is the endogenous driving force of economic growth, and the economy can achieve sustained growth through knowledge accumulation (Yan Chengliang, 2017). Generally speaking, technological innovation is often materialized in the new capital. When the capital continues to accumulate, it will be reflected through technological progress and innovation to promote the realization of economic growth (Dou Jianchun, Feng Tao \& Yang Jianfei, 2015). Scientific and technological innovation represented by knowledge and technology is renewable and infinite, and can promote regional economic growth through the renewal of knowledge and technology (Liu Lin \& Zhang Yong, 2019). Scientific and technological innovation will directly or indirectly promote long-term economic growth by means of innovation spillover effects and total factor productivity or labor productivity improvement (Han Junhua, Han Heyang \& Zhou Quan, 2018).

At the same time, many scholars have pointed out that scientific and technological innovation is the technological driving force to promote industrial upgrading. From the perspective of the enterprise, in order to obtain more profits, enterprises will pay more attention to the research and development and innovation investment of new products, and will produce new products or generate new skills of enterprises, thereby promoting economic growth. And technological innovation creates new products, which first changes the original industrial sector, then the original industrial structure. That is to say, the emergence 
of new products or services can effectively promote the development of production specialization, promote industrial upgrading, and provide power for industrial upgrading (Zhang Yaohui, 2002). Innovation and technological progress make the factors of production in different industries reallocate to optimize the industrial structure and improve the efficiency of resource use. At this time, the allocation of resources is developing in a more reasonable direction, and the productivity of factors will inevitably improve. The Pareto improvement process of resource allocation will be realized until the marginal output of factor input in all sectors is equal and Pareto optimum is achieved, which is also the balance of industrial structure (Chen Deyu, Tang Yonggang \& Zhang Shaohe, 2018). Therefore, industrial upgrading is an endogenous variable of economic growth, and the status of industrial upgrading affects the speed of economic growth.

It can be seen that scholars at home and abroad have realized that scientific and technological innovation can promote industrial upgrading and economic growth. We clarify this promotion as endogenous driving force, that is, the promotion of scientific and technological innovation on industrial upgrading and economic growth is from the inside to the outside, and it is a significant and positive promotion.

\subsection{Industrial Upgrading is the Inevitable Result of Economic Growth and Scientific and Technological Innovation}

Ezioni analyzed the American industry and concluded that the US industrial upgrading, economic growth and scientific and technological innovation are relatively synchronized. Industrial upgrading can provide new impetus for American economic growth through the transformation of old and new momentum. At the same time, industrial upgrading will also trigger huge technological demand and force technological upgrading to support industrial upgrading (Ezioni, 1983). Kagermann took the industrial upgrading of German manufacturing industry as an example, and found that the steady growth of German economy provides the material basis and transformation space for industrial upgrading. The German craftsmanship and technological progress make the technological content of manufacturing industry higher. Naturally, the replacement of old and new technologies has been completed, and the overall upgrading of the industry has been promoted by technological upgrading (Kagermann, 2015).

Domestic research and economic development practice also show that scientific and technological innovation and economic growth will inevitably promote industrial upgrading. Li Zheng and Yang Siying studied the economic development practices of China's eastern, central and western regions. Based on the endogenous growth theory, through empirical analysis, they found that there is a virtuous circle of mutual promotion and interdependence between regional economic growth, scientific and technological innovation and industrial upgrading in the eastern region, that is, economic growth and scientific and technological innovation can act on industrial upgrading (Li Zheng \& Yang Siying, 2017). Xia Yeling and He Gang made an empirical analysis based on the coordination measurement model of composite system, and pointed out that the rapid growth of industrial economy and increasing returns to scale will inevitably induce industrial technological progress, and form industrial linkages and clusters, thus promoting industrial upgrading (Xia Yeling \& He Gang, 2018). Scientific and technological innovation can increase the contribution rate of technology through technology diffusion effect, and gradually replace backward industries. Economic growth can force industries to develop from low to high through the evolution of industrial structure (Xu Yinliang \& Wang Huiyan, 2018).

Therefore, a country's economic growth and scientific and technological development will drive the industry to upgrade spontaneously and effectively. Industrial upgrade is the inevitable outcome of the country's economic growth and technological development to a certain extent.

\subsection{Economic Growth is the Material Guarantee of Scientific and Technological Innovation and Industrial Upgrading}

Scientific and technological innovation and industrial upgrading inevitably require a large amount of material input, which depend on economic growth. Economic growth is a process of total accumulation. With the continuous expansion of the total economic volume, most regions rapidly accumulate funds and talents, which led to the increase of innovative resources and innovative achievements. It also provides a guarantee for the application of scientific and technological innovation achievements, and promotes the 
level of scientific and technological innovation (Song Wenyue \& Ren Baoping, 2019). The increase of economic aggregate will inevitably promote the increase of fiscal revenue and tax revenue, promote government departments to play the leading role of innovation-driven development strategy, increase government investment in research areas with less investment, increase the speed of investment in innovative resources, accelerate the optimization of the allocation of innovative resources, and ensure the smooth progress of scientific and technological innovation (Hong Yinxing, 2017).

At the same time, Kuznets pointed out that the growth of economic aggregate will lead to changes in the structure of the sector, and the human, material and financial resources generated by economic growth will be invested in the industry to provide material guarantee for industrial development. In other words, the three industrial structures will evolve toward the trend of "two, one, three," "two, three, one" to "three, two, one" (Kuznets, 1955). At present, China's economy is undergoing such changes. As the economy develops to a certain stage, the accumulated production factors such as capital and labor will be transferred to more advanced industries. That is to say, the traditional industrial technology will gradually age, the efficiency will be lower, the market will be close to saturation, and emerging industries will gradually develop. After the economic growth reaches a certain stage, it is necessary to upgrade the industry (Li Zheng \& Yang Siying, 2015). Therefore, economic growth provides an effective material carrier and industrial space for industrial upgrading.

\section{Conclusion}

This paper reveals the interactive mechanism of scientific and technological innovation, industrial upgrading and economic growth, and points out that there is a positive interaction between scientific and technological innovation, industrial upgrading and economic growth. That is, scientific and technological innovation can promote industrial upgrading and economic growth, which is endogenous power; industrial upgrading is the natural product of economic growth and scientific and technological innovation, which is the inevitable result; economic growth can provide external support for scientific and technological innovation and industrial upgrading, which is the material guarantee.

Acknowledgements. The work of this paper is supported by 1.Yangtze University Youth Fund Project "Research on the Impact of Financial Ecology Environment on Corporate Financing Constraints under the Background of Supply Side Reform" (2016cqn19), project leader: Ding Jiajun; 2. Yangtze University Social Science Fund Project "Port Construction Fee Payment Information Declaration Management Research" (2015csy001), project leader: Chen Sihang.

\section{Reference}

1. P. M. Romer (1986), "Increase Returns and Long-run Growth," The journal of political economy, vol.94, no.5, pp. 1002-1037.

2. R. E. Lucas (1988), "On the Mechanics of Economic Development," Journal of monetary economics, vol.22, no.1, pp. 3-42.

3. Cheng Yu and Chen Xue (2013), "Innovation Driven Growth in China: Decomposition of HIDZs Total Factor Productivity Growth," Journal of China soft science magazine, no.11, pp. 26-39.

4. C. Clark(1960), "The Conditions of Economic Progress," Journal of Population, no.15, pp.374-375.

5. A. O. Hirschman (1958), "The Strategies of Economic Development," in New Haven, Conn. Yale University Press, pp. 56-98.

6. World Commission on Environment and Development, translated by Wang Zhijia and Ke Jinliang (1997), "Our Common Future," in Changchun. Jilin peoples Press, pp.89-95.

7. Yan Chengliang (2017), "Analysis on Driven Force of China's Economic Growth under the New Normal," Journal of social sciences in Chinese higher education institution, no.6, pp. 44-51+154.

8. Dou Jianchun, Feng Tao and Yang Jianfei(2015), "Technological Innovation, Population Growth and Economic Growth in Chinese History," The journal of world economy, vol.38, no.7, pp. 143-164.

9. Liu Lin, Zhang Yong(2019),"An Analysis on the Spillover Effect of Science and Technology Innovation Input on Regional Economic Growth in China ," Journal of East China Economic Management, vol.33, no.01, pp. 62-66. 
10. Han Junhua, Han Heyang and Zhou Quan(2018), "A Research on the Economic Growth Effect,Operation Mode and Risk Management Path of Science and Technology Financial Innovation in China," Scientific Management Research ,vol.36, no.3, pp. 102-105.

11. Zhang Yaohui(2002), "Industrial Innovation: Industrial Upgrading Model in the New Economy in China," The journal of quantitative \& technical economics , no.1, pp. 14-17.

12. Chen Deyu, Tang Yonggang, Zhang Shaohe (2018), "Empirical Analysis of Industrial Structure Transformation and Upgrading, Financial Science and Technology Innovation and Regional Economic Development in China," Journal of science and technology management research,vol.38, no.15, pp. 105-110.

13. A. Ezioni (1983), "Reindustrialization of America," Review of Policy Research, vol. 2, no.4, pp. 677-1371.

14. H. Kagermann (2015), "Change Through Digitization-Value Creation in the Age of Industry 4.0," in Management of Permanent Change. Springer Fachmedien Wiesbaden, pp. 115-121.

15. Li Zheng and Yang Siying (2017), "Science and Technology Innovation、Industrial Upgrading and Economic Growth in China: Interactive Mechanism and Empirical Test," Jilin university journal social sciences edition, vol. 57, no.3, pp. 41-52+204-205.

16. Xia Yeling and He Gang(2018), "Measurement of Synergy between China's Scientific and Technological Innovation and Industrial Upgrading," Journal of science and technology management research, vol.38, no.8, pp. 27-33.

17. Xu Yinliang and Wang Huiyan(2018), "Research on Performance Evaluation of China's Provincial Science and Technology Innovation Drive Industry Upgrade," Journal of macroeconomics, no.8, pp. 101-114+158.

18. Song Wenyue and Ren Baoping (2019), "Evaluation of Innovation Driven Ability and Its Influencing Factors Analysis in China's Provincial Regions," Statistics and Information Forum, vol.34,no.1, pp. 73-82.

19. Hong Yinxing (2017), "Analysis of Science and Technology Innovation Stage and its Innovation Value Chain in China," Journal of economist, no.4, pp. 5-12.

20. S. S.Kuznets (1955), "Economic growth and income inequality," The journal of American Economic Review, vol.45, no.1, pp. 1-28.

21. Li Zheng and Yang Siying (2015), "Innovation Input, Industrial Structure and Economic Growth in China," Journal of seeking truth, vol.42, no.4, pp. 61-67. 